\title{
Presbyopia: An Animal Model and Experimental Approaches for the Study of the Mechanism of Accommodation and Ocular Ageing
}

\author{
L. Z. BITO, P. L. KAUFMAN,${ }^{*}$ C. J. DEROUSSEAU† and J. KORETZ $\ddagger$ \\ New York, USA
}

\begin{abstract}
Summary
During the last hundred years, observations on normal and a few aniridic human eyes, together with population studies on the age-dependent decline in accommodative amplitude, resulted in the formulation of theories of human accommodation, and led to the concept that presbyopia is an inevitable consequence of ageing. However, such studies failed to substantiate these theories and concepts or to reveal the fundamental mechanisms of accommodation and its age-dependent loss. Detailed understanding of these mechanisms and the environmental, dietary, and behavioural factors that may influence the development of presbyopia will require controlled studies and, in some cases, invasive experimental manipulations that can only be achieved through the use of an animal model. This paper reviews some of the evidence indicating that the rhesus monkey is a highly suitable primary animal model for such studies, as well as for studies on other aspects of ocular ageing, and reviews some of the techniques and experimental approaches that have already been adapted or developed for such studies.
\end{abstract}

Most classic papers on the development of presbyopia and on other aspects of agedependent ocular disorders have been based on clinical observations. These led to the formulation, more than a hundred years ago, of the basic theory of human visual accommodation, ${ }^{1}$ and to some of the more recent, sometimes conflicting modifications or expansions of that theory. ${ }^{2}$ Such observations also yielded important information on the time course of presbyopia development, ${ }^{3,4}$ established that the human lens continues to grow throughout life,,$^{5,6}$ and revealed that the lens is subject to alterations in its basic physical properties. ${ }^{7,8,9}$ Despite all of these observations, the mechanisms of accommodation and its age-dependent loss remain to be established and will have to await experimental studies on suitable animal models.

The animals most commonly used for studies on ageing are species such as rats and mice, which have short lifespans and exhibit characteristic ageing changes over a period of months that may take years or decades to develop in humans. These shortlived species are, however, of little use for studies on most aspects of ocular ageing because their eyes differ in morphological details from the eyes of primates and are too small for most available techniques of clinical ophthalmology and experimental eye research.

Because of the requirement for larger eyes,

Department of Ophthalmology, College of Physicians and Surgeons, Columbia University, NY.

* Department of Ophthalmology, University of Wisconsin, Madison, WI.

$\dagger$ Department of Anthropology, New York University, NY.

$\ddagger$ Department of Biology, Rensselaer Polytechnic Institute, Troy, NY.

Correspondence to: Laszlo Z. Bito, PhD, 630 West 168th Street, New York, NY 10032. 
most areas of eye research have adopted the rabbit as the primary experimental animal. The inadequacy of this species for most areas of eye research, because of the atypical responses of the rabbit eye to trauma, has already been pointed out. ${ }^{10}$ Even the large volume of data that has already been accumulated on rabbit eyes is of very limited value for the understanding of ocular ageing since virtually all rabbits used in eye research are only a few months old, which is a very small fraction of the well over 10 year lifespan of this lagomorph. ${ }^{11}$ Moreover, even if aged rabbits were available for research, they would be of limited use with regard to studies on presbyopia since this species has a non-accommodating visual system. ${ }^{12,13}$ The same limitation also pertains to use of the large volume of biochemical data that has been generated on bovine lenses, since the bovine eye, like that of rabbits and most other herbivores, is adapted for monitoring visual functions that are not consistent with, and are not likely to be associated with, accommodation. ${ }^{14}$

In contrast, carnivores in general are reputed to have a small but physiologically significant accommodative amplitude. It is generally accepted that cats, the carnivores most frequently used in biomedical research, have an accommodative amplitude ranging from 2 to 4 diopters (D) ${ }^{15,16}$ although some investigators have reported as much as $12 \mathrm{D}$ for cats of unspecified ages. ${ }^{17,18}$ However, because accommodation in cats is said to be achieved primarily by lenticular displacement, ${ }^{15,19}$ this species cannot be regarded as a suitable model for the study of human accommodation, which involves lenticular deformation.

The largest accommodative amplitudes achieved by lenticular deformation have been reported among birds, particularly those that must pursue their prey under water. ${ }^{20}$ In such avian eyes, the very large and rapid lenticular deformation required to switch from vision in air to vision under water is achieved in part by a direct force applied by the ciliary body on the annular pad of the lens, a structure that does not exist in primates, and in part by the force exerted by the iris margin on the anterior surface of the lens to form a lenticonus. ${ }^{21,22}$ Furthermore, in these avian eyes, both the ciliary muscle and the iris sphincter are nicotinically innervated striated muscles, as opposed to the muscarinically innervated smooth muscles in primates. ${ }^{20,23,24}$

Several species of primates have significant accommodative amplitudes. ${ }^{25-28}$ Törnqvist $^{26}$ mentioned that cynomolgus monkeys that were estimated to be older on the basis of appearance and tooth wear, had smaller accommodative amplitudes than ones judged to be younger by the same inadequate criteria. However, most studies on the accommodative amplitudes of birds, reptiles, fishes, and mammals have not considered age. Hence, we have virtually no information on the vulnerability of the different types of accommodative mechanisms to ageing. In the absence of such data, it has been argued, on the basis of behavioural considerations and the known differences in the mechanisms of accommodation among different classes of vertebrates, that the piscine accommodative mechanism is likely to be the least vulnerable and the primate mechanism the most vulnerable to presbyopia. ${ }^{29}$ These considerations suggest that a suitable primary animal model for the understanding of human accommodation and its age-dependent loss must be found among primates.

Gorillas or chimpanzees may be regarded as our closest relatives. However, the availability of these animals is very limited, their cost is prohibitive, and their handling is most difficult. Of the smaller, more readily available primates, there are several species of macaques that have been used effectively in medical research. In eye research, the largest body of information has been collected on rhesus (Macaca mulatta) and cynomolgus (Macaca fascicularis) monkeys. There are several large rhesus colonies, some of which have genealogical and census records dating back for half a century. These offer a unique advantage with regard to the study of presbyopia and other aspects of ageing because they contain animals of known ages, spanning the whole age spectrum.

A survey of a colony of free-ranging rhesus monkeys maintained on the island of Cayo Santiago in Puerto Rico aimed at establishing the relationship between ocular growth and intraocular pressure, showed that the rhesus lens, like the human lens, continues to grow 
throughout adulthood..$^{27,30}$ Since continuous lenticular growth may be one important contributor to presbyopia and, in fact, may be caused by accommodative efforts, ${ }^{14}$ a population survey was designed to study specifically the relationship between age and accommodative amplitude in this species. This first survey of age-dependent changes in accommodative amplitude was conducted on caged animals at Madison WI, where much better laboratory facilities than those on the island of Cayo Santiago were available for such studies and where the animals that were given both cholinergic and adrenergic drugs to induce accommodation yet minimise pupillary constriction could be effectively monitored after their examination.

Age-dependent decline in accommodative amplitude leading to a complete loss of this function was found in this initial survey of caged rhesus monkeys. ${ }^{27}$ In addition, accommodation was found to be associated with an increase in lenticular axial thickness. These initial observations that strongly suggested a possible similarity between the rhesus and the human eye with respect to the mechanism of accommodation and its age-dependent loss led us to form a multi-university consortium, which has been funded by the National Eye Institute (NIH, USPHS), to establish the suitability of the rhesus monkey as an animal model for presbyopia research. Our studies used two rhesus colonies that are maintained under different environmental conditions: the unsheltered, free-ranging animals kept under a tropical climate and bright sunlight on the island of Cayo Santiago and the caged animals kept in air-conditioned rooms under artificial light in Wisconsin. These two colonies were used to provide an opportunity to investigate the effects of environmental conditions such as light intensity and ambient temperature, which are reputed to contribute to or cause cataractogenesis $^{31,32}$ and to hasten the development of presbyopia. ${ }^{4}$ This was regarded to be an important aspect of our study since the influence of these factors cannot be effectively studied in human populations, which rarely, if ever, are exposed uniformly to such diverse environmental conditions. We shall review here briefly some of the evidence we have accumulated in support of the suitability of the rhesus monkey for the study of human ocular ageing and presbyopia development. We shall also review some of the relevant techniques and experimental approaches we have already developed or adapted to this species and some of the results we have obtained with regard to the mechanism of accommodation and presbyopia development, as well as with respect to other aspects of ocular ageing.

\section{Non-invasive ageing studies on normal rhesus eyes}

Our first studies aimed at basic characterisation of ageing changes in the eye were done on normal rhesus monkeys, using non-invasive techniques. These included slit-lamp biomicroscopy and photography, retinoscopy, tonometry, ${ }^{33.34}$ corneal pachymetry, endothelial specular microscopy, ${ }^{35}$ resting and maximally accommodated refraction, ${ }^{27}$ A-scan ultrasonic measurement of axial dimensions, ${ }^{27,30}$ and pupillography as well as anthropometric and functional measures of some non-ocular aspects of ageing such as body size, joint mobility, and skin elasticity. We have also adapted the Scheimpflug principle to slit-lamp photography, as first described by Brown, ${ }^{36}$ to obtain information on the developmental and ageing changes in resting lens curvatures.

These Scheimpflug photographic studies of the rhesus anterior segment at resting refraction under ketamine anaesthesia showed that lenticular ageing in the rhesus eye is associated with changes in shape that are very similar to those that occur in the human eye: ${ }^{37}$ lens thickness increases linearly with age past the developmental period and the anterior chamber shallows by the same amount, while the location of the posterior lens surface relative to the cornea remains essentially unchanged. These findings are consistent with previously published ultrasonic measurements showing a gradual decrease in axial thickness of the rhesus lens during the developmental years, followed by a continual increase in lens thickness throughout the rest of the lifespan. ${ }^{27,30}$ Most importantly, these photographic studies showed that both lens surfaces develop an increased sharpness of curvature with increasing age, as Brown ${ }^{36,38}$ 
first reported in humans. Finally, it should be noted that rhesus lens curvature, irrespective of accommodative state or age, can be fitted to a second order polynomial where the bx term is close to or equal to zero; this is again similar to the mathematical description of human lens shape at all ages and accommodative levels. ${ }^{39}$

Using carbachol to induce accommodation in these population surveys, we have shown that juvenile rhesus monkeys have an extraordinarily large accommodative amplitude of more than $30 \mathrm{D}$, which decreases with age so that in most animals over the age of 25 to 30 years it is reduced to zero. ${ }^{27}$ Since carbachol is a potent miotic, it was necessary to pretreat the eyes with an adrenergic agonist to prevent complete pupillary constriction, which would have precluded further refraction. However, even a maximal dose of an adrenergic agonist does not yield a sufficiently large pupil to allow Scheimpflug photography of both lenticular surfaces during carbachol-induced accommodation. Furthermore, even a fully dilated iris does not allow the viewing of the zonules and ciliary body. We have therefore undertaken more detailed studies on a smaller subset of iridectomised rhesus monkeys.

\section{The utility of the iridectomised rhesus eye for the study of accommodation}

The use of the iridectomised eye for visualising the process of accommodation was demonstrated by observations made over the past century on a few aniridic human eyes. ${ }^{1,2}$ Complete congenital aniridia is, however, a rare condition among humans that is accompanied, at least in some cases, by deficiencies in the accommodative apparatus. ${ }^{2}$ In humans, surgical iridectomy of sufficient size to reveal the entire accommodative apparatus is rare. On the other hand, complete surgical iridectomy can be performed on monkey eyes relatively easily with a high rate of success. ${ }^{40}$ This procedure made it possible to obtain Scheimpflug slit-lamp photographic documentation of lenticular shapes at different amplitudes of drug-induced or electricallyinduced accommodation.

Our studies in iridectomised rhesus eyes demonstrate that the accommodative mechanism in the rhesus monkey is similar to that reported for the human eye: ${ }^{37}$ with increasing accommodation, the anterior chamber depth decreases, the lens becomes thicker along its polar axis and both lens surfaces become more sharply curved, while the posterior lens surface remains in approximately the same position relative to the cornea. The changes in each of these parameters (except the location of the posterior lens surface) are linear up to 20 diopters of accommodation, and the slope of this linear relationship is independent of age. This indicates that as in humans, the change in lens shape per diopter of accommodation remains constant throughout a rhesus monkey's lifespan, while the magnitude of the accommodative amplitude declines during the pre-presbyopic years.

\section{Stimulation of the Edinger-Westphal (EW) Nucleus}

Although induction of accommodation with cholinomimetic drugs is a simple noninvasive technique for large-scale population studies on the maximum accommodative amplitude of primates, it is not suitable for measuring the rate of changes associated with accommodation and disaccommodation. Measurements of these rates as a function of age will obviously be essential for the understanding of presbyopia development. However, it is impossible to measure the rate of ciliary muscle contraction in normal human subjects. Even the rate of lenticular changes is difficult to estimate because the rate of changes in the effector system itself can be overshadowed by variabilities in the afferent and central mechanism. We have, therefore, adapted a more direct stimulation technique to measure these rates on iridectomised rhesus eyes.

Electrodes implanted into different midbrain centres have been used by several investigators to stimulate accommodation in experimental animals..$^{25,41,42}$ Since, at this point, our primary interest is in the effector mechanism itself, we have used bipolar electrodes permanently implanted in the EW nucleus to minimise the number of neuronal connections interposed between the site of stimulation and the effector muscle, thereby minimising the duration and, presumably, the variability of the delay time..$^{43}$

Implantation of the electrode is done under stereotaxic control through a small midline 
craniotomy. The ventricular system is visualised by contrast ventriculoradiography to estimate the coordinates of the EW nucleus in each animal. A bipolar electrode is then positioned stereotaxically on the midline above the nucleus and lowered in $0.5 \mathrm{~mm}$ steps. Positional adjustments can be made as dictated by the radiographic localisation of the electrode in relation to the ventricular system and by the presence and symmetry of the accommodative and pupillary responses, as well as eye movements, until maximum symmetric accommodation is achieved. Such a controlled empirical approach is required because the brain proportion in monkeys, unlike that in inbred rats, exhibits considerable interindividual variation. After a few days of recovery, stimulation of the $\mathrm{EW}$ nucleus at $100 \mathrm{~Hz}$ yields a reproducible relationship between stimulus voltage and accommodative amplitude that is maintained for at least six months.

We have already used this technique to compare the magnitude of electrically and pharmacologically induced accommodation. ${ }^{43}$ Although carbachol-induced accommodation shows a greater amplitude than EW stimulation $^{43}$, none of the measured changes in lenticular shape considered were statistically different with the two stimulation techniques. We have also found that as the monkeys age, the accommodative response to both stimuli declines, as does the difference between them. It remains to be determined whether or not this implies that carbachol can cause a greater accommodative change than the maximum amplitude physiologically available to each animal. The possibility cannot be excluded that stimulation of the EW nucleus underestimates the maximum available accommodative amplitude, since a single electrode in the EW nucleus may not recruit all neurons that innervate the ciliary muscle. Nonetheless, this technique seems well-suited for studying the dynamics of accommodation and disaccommodation, since the onset and termination of the stimulus can be accurately registered, and since the reaction as compared to drug-induced accommodation is rapid and quickly reversible.

\section{Immobilisation of the globe}

Eye movements can prevent real-time monitoring of the rates of accommodation and disaccommodation both in experimental animals and human subjects. ${ }^{44}$ This problem also greatly complicated our first attempt to measure the rates of lenticular deformation and ciliary body movements from video recordings (see below), since stimulation of the EW nucleus almost invariably caused some eye movements. For this reason, we adapted the botulinum toxin technique developed by Scott and co-workers ${ }^{45.46}$ for the treatment of strabismus in humans. In a group of five rhesus monkeys, such injection of the medial rectus muscles prevented nearly all eye movement, even when the voltage used for stimulation of the EW nucleus exceeded that required to cause maximal accommodation. In some animals, however, it was also necessary to inject the superior or inferior rectus muscle to achieve sufficient stability of the globe. It is evident from these preliminary experiments that the use of botulinum toxin to induce paralysis of the extraocular muscles allows continuous recording of the dynamics of accommodation and disaccommodation in rhesus monkeys.

\section{Scheimpflug and gonioscopic continuous video recording techniques}

So far, we have developed two video recording techniques for studying the time course of events associated with accommodation and disaccommodation. The Scheimpflug principle is used by tilting the angle of the vidicon tube with respect to the lens of the video camera to make recordings of optical slit images of the cornea and lens through the optic axis..$^{43}$ In iridectomised eyes, virtually the whole anterior surface of the lens and most of the posterior surface of the lens can be viewed in focus simultaneously and recorded with this technique while accommodation is induced by stimulation of the EW nucleus. The real timecourse of changes in the anterior and posterior curvatures of the lens and their positions relative to the cornea can be measured from this type of recording.

In the second technique, video recordings of the ciliary processes, zonules, and the equatorial region of the lens are made through a 
Swan-Jacob gonioscopy lens, using the same video camera but without employing the Scheimpflug principle, to record the time course of ciliary body movement with respect to the onset and termination of EW nucleus stimulation. In both cases, the onset and termination of stimulation is coded on the video tape through a time and date generator electrically connected to the stimulator.

\section{The dynamics of lenticular and ciliary body deformations during accommodation and disaccommodation}

Preliminary frame-by-frame computerassisted analysis of Scheimpflug and gonioscopic video recordings demonstrates that it is possible to measure the following parameters of the dynamics of accommodation:

(1) delay time between onset of EW nucleus stimulation and onset of lenticular deformation, movement of the anterior lens surface toward the cornea, ciliary muscle contraction and, in the case of maximum stimulation, slackening of the zonule fibres;

(2) delay time between termination of stimulation and the onset of reversal of each of these processes;

(3) the rates of lenticular deformation, lenticular displacement relative to the cornea, and ciliary body movement in terms of displacement of a fixed point on the ciliary body surface toward the optic axis as measured from the scleral wall;

(4) the rates of reversal of each of these processes.

We are currently developing gonioscopic techniques to obtain videorecordings of anterior-posterior ciliary body movements parallel to the scleral wall by viewing the ciliary body along a more coronal plane.

Based on one set of experiments completed on six rhesus monkeys ranging in age from 3 to 23 years, it is apparent that differences between the delay times preceding accommodation and disaccommodation are similar or identical, but that the rate of disaccommodation at any age is more rapid than the rate of accommodation. This finding is consistent with the concept that effective and rapid disaccommodation is more important for pri- mate visual adaptation than the speed and extent of accommodation..$^{29}$ Moreover, these preliminary observations show that, contrary to widely accepted but not adequately supported concepts ${ }^{47}$, the age-dependent loss of accommodative amplitude is accompanied by a decrease in ciliary body movement. In older animals, which responded to maximum drug or electrical stimulation with only a few diopters of accommodation, there was little or no observable ciliary body movement. These techniques are also applicable to the study of the fatiguing of the accommodative process during continuous or intermittent stimulation.

\section{In vivo visualisation of the zonule fibres}

We have also used a gonioscopic videorecording technique to visualise the suspensory ligaments of the lens by making empirical adjustments in illumination. ${ }^{43}$ Induction of accommodation by stimulation of the EW nucleus when the best-albeit still far from clear-visualisation was obtained, revealed a slackening, or even folding, of some zonule fibres when maximal ciliary body contraction was approached or achieved.

In vitro studies demonstrated that dichlorotriazinyl fluorescein, the dye previously used to permanently stain collagen fibres in the corneal stroma by covalent binding $^{48}$, can also be used to stain the suspensory ligaments and the capsule of the lens of various species (Miranda and Bito, unpublished observations). So far, this dye has been superfused in vivo over the suspensory ligament of only one iridectomised cynomolgus monkey eye. Good fluorescein staining of the suspensory ligaments and lens capsule has been observed by slit-lamp gonioscopy for more than three months without evidence of any loss of the stain, indicating that this is a promising approach for improving the videogonioscopic visualisation of these transparent, delicate structures that are otherwise very difficult to see. ${ }^{49}$

The occurrence of other ocular abnormalities and age-related disorders in rhesus monkeys In addition to the correspondence between rhesus eyes and human eyes with respect to their vulnerability to presbyopia, which fol- 
lows a similar time course relative to lifespan and is associated with similar lenticular changes in both species, the rhesus eye also exhibits other ageing changes that are characteristic of human ocular ageing. Thus, senile cataracts, ocular hypertension, primary openangle glaucoma ${ }^{50}$, and peripheral cystoid retinal degeneration, as well as both wet and dry senile macular degeneration (P. L. Kaufman, unpublished observation), also occurred in the animals studied in our presbyopia surveys. All of these changes strongly resemble the analogous human entities. Developmental variants, including lenticulovitreo-retinal vascular remnants (Mittendorf dot; Bergmeister papilla), anterior embryotoxon, and congenital cataract were also found occasionally. Furthermore, the previously described macular and perimacular alterations ${ }^{51}$, as well as myelinated retinal nerve fibres, were observed in rhesus monkeys kept in the airconditioned quarters of the primate facilities at Madison WI, as well as in those kept in Puerto Rico, where light intensity can be over one-thousand-fold higher than the light intensity maintained indoors.

\section{Nonocular aspects of ageing in rhesus monkeys}

With the long-term maintenance of rhesus monkeys in primate research centres, this species has become an important model for many other aspects of human ageing, especially changes in cognitive behaviour. ${ }^{52,53}$ In order to establish the relationship between the ocular changes described here and other aspects of a generalised ageing process, we have also examined parameters of nonocular ageing in our surveys, which by now include more than four hundred rhesus monkeys. Age-related declines in joint mobility ${ }^{54}$, bone mass ${ }^{55}$, and skin elasticity (Ochoa, DeRousseau, Sade, and Kaufman, unpublished observations) were observed, as were age-related increases in degenerative joint disease ${ }^{54,56}$, especially in the vertebral column. ${ }^{57}$ Many of these changes are remarkably similar to the well-known changes that characterise human ageing. Some of these changes appear to proceed at rates similar to those noted for loss of accommodation with age in the same rhesus populations $^{57}$, and therefore may be linked through some common basic mechanisms of general ageing. It should be noted, however, that accommodation appears to be unique in one regard: it is the only nonreproductive function that is completely lost in both rhesus monkeys and humans well before the end of the respective lifespans of these species. ${ }^{29}$ Correlation analyses suggest that of the nonocular parameters examined, loss of joint mobility and loss of skin elasticity are particularly well correlated with loss of accommodative amplitude in rhesus monkeys, suggesting that connective tissue changes ${ }^{58}$ may make an important contribution to the age-dependent loss of accommodative amplitude.

\section{Conclusions}

Accommodation in rhesus monkeys is achieved by a process that is identical in all important aspects, and apparently in most of its details, to the accommodative process of the human eye. The age-dependent loss of accommodation in these two species is also similar with regard to the associated morphological changes as well as in time-course relative to their respective life spans. Since the lifespan of the rhesus monkey is about onethird of the human and since juvenile rhesus monkeys have a larger accommodative amplitude than human juveniles, the actual loss of accommodative amplitude per year is several times greater in the rhesus monkey. Furthermore, as opposed to humans, environmental and dietary conditions of rhesus monkeys can be controlled throughout their lifespans. Thus, the rhesus monkey represents an excellent model for the study of the mechanism of human accommodation and its age-dependent loss and offers an opportunity to establish the true influence of factors such as temperature and visible or ultra-violet light intensity on lenticular ageing and presbyopia development.

Last but not least, since rhesus monkeys have been found to develop most other agedependent ocular disorders that are known to affect the human eye, they can also be expected to help elucidate the mechanisms of cataractogenesis and glaucoma and their possible relationships to the lenticular and ciliary body changes that contribute, typically at an earlier age, to the development of presbyopia. 
We wish to thank the staffs of the Wisconsin Regional Primate Center (supported by RR-00167NIH) and the adjacent facility of the Primate Laboratory of the Psychology Department of the University of Wisconsin in Madison, as well as the staff of the Caribbean Primate Research Center (supported by RR-01293NIH) in Puerto Rico for the use of their rhesus monkeys and for their assistance with our studies, which were supported by Consortium Grant EY 04146 (National Eye Institute; NIH, U.S.P.H.S.). Thanks are also extended to Dr. Olivia C. Miranda for her invaluable assistance with the preparation of this manuscript.

\section{References}

${ }^{1}$ Helmholtz H: Handbuch der Physiologischen Optik. Allgemeinen Encyklopadie der Physik. Band IX. von Gustav Karsten, Leipzig, Vol. 1, 1866. (Third edition translated into English.) In Southall JPC ed. The Optical Society of America. New York: 1924, 1925.

${ }^{2}$ Fincham EF. The mechanism of accommodation. $\mathrm{Br}$. J. Ophthalmol. VIII (Monograph Suppl): 1937; 7-80.

${ }^{3}$ Duane A. Studies in monocular and binocular accommodation with their clinical applications. Am. J. Ophthalmol. 1922; 5: 865-77.

${ }^{4}$ Miranda MN. The geographic factor in the onset of presbyopia. Trans. Am. Ophthalmol. Soc. 1979; 77: 603-21.

${ }^{5}$ Smith P. VI Diseases of crystalline lens and capsule. 1. On the growth of the crystalline lens. Trans. Ophthalmol. Soc. U.K. 1883; 3: 79-99.

${ }^{6}$ Scammon RE, and Hesdorffer MB. Growth in mass and volume of the human lens in postnatal life. Arch. Ophthalmol. 1937; 17: 104-12.

${ }^{7}$ Fisher RF. Presbyopia and the changes with age in the human crystalline lens. J. Physiol. 1973; 228: 765-79.

${ }^{8}$ Weale RA. A biography of the eye. London: HK Lewis and Co., Ltd. 1982.

${ }^{9}$ Maisel $\mathrm{H}$ ed. The Ocular Lens. Structure, Function, and Pathology. New York/Basel: Marcel Dekker, Inc. 1985.

${ }^{10}$ Bito LZ. Species differences in the responses of the eye to irritation and trauma: a hypothesis of divergence in ocular defense mechanisms, and the choice of experimental animals for eye research. Exp. Eye Res. 1984; 39: 807-29.

"Altman PL, and Dittmer DS. Biology Data Book. Washington, DC. Federation of American Societies for Experimental Biology. 1964.

${ }_{12}^{12}$ Prince JH. The Rabbit in Eye Research. Springfield: Charles C. Thomas 1964.

${ }^{13} \mathrm{Olmsted}$ JMD. The role of the autonomic nervous system in accommodation for far and near vision. J. Nerv. Ment. Dis. 1944; 99: 794-8.

${ }^{14}$ Bito LZ, Miranda OC. Presbyopia: The need for a closer look. In: Stark L, Obrecht G eds. Presbyopia: Recent Research and Reviews from the
Third International Symposium. New York: Churchill/Professional Press 1987.

${ }^{15} \mathrm{O}$ 'Neill WD, Brodkey JS: Linear regression of lens movement with refractive state. Arch. Ophthalmol. 1969; 82: 795-9.

${ }^{16} \mathrm{Marg}$ E, Reeves JL: Accommodative response of the eye of an aged cat to electrical stimulation of the ciliary ganglion. J. Opt. Soc. Am. 1955; 45: 926-8.

${ }^{17}$ Olmsted JMD, Morgan MW: The influence of the cervical sympathetic nerve on the lens of the eye. Am. J. Physiol. 1941; 133: 720-3.

${ }^{18}$ Lovasik JV, Beauchamp R. Ocular accommodation in the cat after electrical stimulation of mesencephalic reticular formation. Am. J. Optom. Physiol. Opt. 1982; 59: 726-34.

${ }^{19}$ Hughes A. Observing accommodation in the cat. Vision Res. 1973; 13: 481-2.

${ }^{20}$ Howland HC, Sivak JG. Penguin vision in air and water. Vision Res. 1984; 24: 1905-9.

${ }^{21}$ Goodge WR. Adaptations for amphibious vision in the Dipper (Cinclus mexicanus). J. Morphol. 1960; 107: 79-91.

${ }^{22}$ Meyer DB. The avian eye and its adaptations. In Crescitelli F ed. Handbook of Sensory Physiology. VII/5. The Visual System in Vertebrates. Berlin: Springer-Verlag 1977: 549-611.

${ }_{23}^{23}$ Slonaker JR. A physiological study of the anatomy of the eye and its accessory parts of the English sparrow (Passer domesticus). J. Morph. 1918: 31: 351-459.

${ }^{24}$ Sivak JG, Vrablic OE. Ultrastructure of intraocular muscles of diving and nondiving ducks. Canad. $J$. Zool. 1982; 60: 1588-606.

${ }^{25}$ Chin NB, Ishikawa S, Lappin $\mathrm{H}$, Davidowitz $\mathrm{J}$, Breinin GM. Accommodation in monkeys induced by midbrain stimulation. Invest. Ophthalmol. 1968; 7: 386-96.

${ }^{26}$ Törnqvist G. Effect of topical carbachol on the pupil and refraction in young and presbyopic monkeys. Invest. Ophthalmol. 1966b; 5: 186-95.

${ }^{27}$ Bito LZ, DeRousseau CJ, Kaufman PL, Bito JW. Age-dependent loss of accommodative amplitude in rhesus monkeys: An animal model for presbyopia. Invest. Ophthalmol. Vis. Sci. 1982; 23: $23-31$.

${ }^{28}$ Smith EL III, Harwerth RS. Behavioral measurements of accommodative amplitude in rhesus monkeys. Vision Res. 1984; 24: 1821-27.

${ }^{29}$ Bito LZ, Miranda OC. Presbyopia: Comparative and evolutionary perspectives. Atti della Fondazione Giorgio Ronchi (Suppl). 1987 In press.

${ }^{30}$ DeRousseau CJ, Bito LZ: Intraocular pressure of rhesus monkeys (Macaca mulatta). II. Juvenile ocular hypertension and its apparent relationship to ocular growth. Exp. Eye Res. 1981; 32: 407-17.

${ }^{31}$ Miranda MN. Environmental temperature and senile cataract. Tr. Am. Ophthalmol. Soc. 1980; 78: $255-64$.

${ }^{32}$ Varma SD, Lerman S ed. Proceedings of the First International Symposium on Light \& Oxygen Effects on the Eye. Current Eye Res. 1984; 3: $1-275$. 
${ }^{33}$ Bito LZ, Merritt SQ, DeRousseau CJ. Intraocular pressure of rhesus monkeys (Macaca mulatta). Invest. Ophthalmol. Vis. Sci. 1979; 18: 785-93.

${ }^{34}$ Kaufman PL, Davis GE: Minified Goldmann applanating prism for tonometry in monkeys and humans. Arch. Ophthalmol. 1980; 98: 542-6.

${ }^{35}$ Baroody RA, Bito LZ, DeRousseau CJ, Kaufman PL, Koester CJ: Ocular development and aging. 1. Corneal endothelial cell density and morphology in cats and in free-ranging and caged rhesus monkeys. Invest. Ophthalmol. Vis. Sci. 1986; 27 (Suppl): 70 .

${ }^{36}$ Brown NP. The change in the shape and internal form of the lens of the eye on accommodation. Exp. Eye Res. 1973; 15: 441-59.

${ }^{37}$ Koretz JF, Neider MW, Kaufman PL, Bertasso AM, DeRousseau CJ, Bito LZ: Slit-lamp studies of the rhesus monkey eye: I. Survey of the anterior segment. Exp. Eye Res. 1987; (In press).

${ }^{38}$ Brown NP. The change in lens curvature with age. Exp. Eye Res. 1974; 19: 175-83.

${ }^{39}$ Koretz JF, Handelman GH, Brown NP: Analysis of human crystalline lens curvature as a function of accommodative state and age. Vision Res. 1984; 24: 1141-51.

${ }^{40} \mathrm{Kaufman}$ PL, Lutjen-Drecoll E: Total iridectomy in the primate in vivo: surgical technique in postoperative anatomy. Invest. Ophthalmol. 1975; 14: $766-71$.

${ }^{41}$ Bender MB, Weinstein EA: Functional representation in the oculomotor and trochelar nuclei. Arch. Neurol. Psychiat. 1943; 49: 98-106.

${ }^{42}$ Jampel RS, Mindel J: The nucleus for accommodation in the midbrain of the macaque. Invest. Ophthalmol. 1967; 6: 40-50.

${ }^{43}$ Neider MW, Crawford K, True B, Kaufman PL, Bito LZ: Functional studies of accommodation and presbyopia in rhesus monkeys. Invest. Ophthalmol. Vis. Sci. 27 (Suppl): 1986; 81.

${ }^{44}$ Beauchamp R, Mitchell B: Ultrasound measures of vitreous chamber depth during ocular accommodation. Am. J. Optom. and Physiol. Opt. 1985; 62: $523-32$.

${ }^{45}$ Scott AB, Rosenbaum A, Collins CC: Pharmacologic weakening of extraocular muscles. Invest. Ophthalmol. Vis. Sci. 1973; 12: 924.

${ }^{46}$ Scott AB. Botulinum toxin injection into extraocular muscles as an alternative to strabismus surgery. Ophthalmol. 1980; 87: 1044.
${ }^{47}$ Swegmark G. Studies with impedance cyclography on human ocular accommodation at different ages. Acta. Ophthalmol. 1969; 47: 1186-206.

${ }^{48}$ Davison PF, Galbavy EJ: Fluorescent dyes demonstrate the uniform expansion of the growing rabbit cornea. Invest. Ophthalmol. Vis. Sci. 1985; 26: 1202-9.

${ }^{49}$ Bito LZ, Kaufman PL, Neider M, Miranda OC, Antal P: The dynamics of accommodation (ciliary muscle contraction, zonular relaxation and lenticular deformation) as a function of stimulus strength and age in iridectomized rhesus eyes. Invest. Ophthalmol. Vis. Sci. 28 (Suppl), 1987.

${ }^{50} \mathrm{Kaufman}$ PL, Bito LZ: The occurrence of senile cataracts, ocular hypertension and glaucoma in rhesus monkeys. Exp. Eye Res. 1982; 34: 287-91.

${ }^{5}$ El-Mofty AAM, Eisner G, Balazs EA, Denlinger JL, Gouras P: Retinal degeneration in rhesus monkeys, Macaca mulatta. Survey of three seminatural free-breeding colonies. Exp. Eye Res. 1980; 31: 147-66.

${ }^{52}$ Bowden DM ed. Aging in Nonhuman Primates. New York: Van Nostrand Reinhold Co. 1979.

${ }^{53}$ Davis RT, Leathers CW eds: Behavior and Pathology of Aging in Rhesus Monkeys. New York: Alan R. Liss, Inc. 1985.

${ }^{54}$ DeRousseau CJ, Rawlins RG, Denlinger JL: Aging in the musculoskeletal system of rhesus monkeys: I. Passive joint excursion. Am. J. Phys. Anthropol. 1983; 61: 483-94.

${ }^{55}$ DeRousseau CJ. Aging in the musculoskeletal system of rhesus monkeys: III. Bone loss. Am. J. Phys. Anthropol. 1985; 68: 157-67.

${ }^{56}$ DeRousseau CJ, Bito LZ, Kaufman PL: Age-dependent impairments of the rhesus monkey musculoskeletal and visual systems and apparent behavioral consequences. In: Rawlins $R G$, Kessler MJ eds. The Cayo Santiago Macaques. History, Behavior and Biology. New York: State University of New York Press 1986 Ch 11 pp 23287.

${ }^{57}$ DeRousseau CJ. Aging in the musculoskeletal system of rhesus monkeys: II. Degenerative joint disease. Am. J. Phys. Anthropol. 1985; 67: 17784.

${ }^{58}$ Reiser KM, Rucker RB, Last JA: Age-related changes in connective tissue cross-linking in rhesus monkey lungs. In Davis RT, Leathers CW eds. Behavior and Pathology of Aging in Rhesus Monkeys. New York: Alan R. Liss, Inc. 1985. 